\title{
Leadership $=$ Communication? The Relations of Leaders' Communication Styles with Leadership Styles, Knowledge Sharing and Leadership Outcomes
}

\author{
Reinout E. de Vries • Angelique Bakker-Pieper • \\ Wyneke Oostenveld
}

Published online: 4 October 2009

(C) The Author(s) 2009. This article is published with open access at Springerlink.com

\begin{abstract}
Purpose The purpose of this study was to investigate the relations between leaders' communication styles and charismatic leadership, human-oriented leadership (leader's consideration), task-oriented leadership (leader's initiating structure), and leadership outcomes.

Methodology A survey was conducted among 279 employees of a governmental organization. The following six main communication styles were operationalized: verbal aggressiveness, expressiveness, preciseness, assuredness, supportiveness, and argumentativeness. Regression analyses were employed to test three main hypotheses.

Findings In line with expectations, the study showed that charismatic and human-oriented leadership are mainly communicative, while task-oriented leadership is significantly less communicative. The communication styles were strongly and differentially related to knowledge sharing behaviors, perceived leader performance, satisfaction with the leader, and subordinate's team commitment. Multiple regression analyses showed that the leadership styles mediated the relations between the communication styles and
\end{abstract}

Received and reviewed by former editor, George Neuman.

R. E. de Vries $(\bowtie) \cdot$ A. Bakker-Pieper

Department of Work and Organizational Psychology,

VU University Amsterdam, Van der Boechorststraat 1,

1081 BT Amsterdam, The Netherlands

e-mail: re.de.vries@psy.vu.nl

A. Bakker-Pieper

e-mail: a.bakker@psy.vu.nl

W. Oostenveld

University of Amsterdam, Amsterdam, The Netherlands

e-mail: w.oostenveld@ymere.nl leadership outcomes. However, leader's preciseness explained variance in perceived leader performance and satisfaction with the leader above and beyond the leadership style variables.

Implications This study offers potentially invaluable input for leadership training programs by showing the importance of leader's supportiveness, assuredness, and preciseness when communicating with subordinates.

Originality/value Although one of the core elements of leadership is interpersonal communication, this study is one of the first to use a comprehensive communication styles instrument in the study of leadership.

Keywords Communication styles - Leadership ·

Leadership styles · Charisma - Consideration · Initiating structure - Knowledge sharing - Commitment . Satisfaction with the leader - Perceived leader performance

\section{Introduction}

Several authors have noted that communication is central to leadership (Awamleh and Gardner 1999; Den Hartog and Verburg 1997; Frese et al. 2003; Kirkpatrick and Locke 1996; Riggio et al. 2003; Shamir et al. 1994; Spangler and House 1991; Towler 2003), but, except for studies devoted to oratory skills and content in highly specific speech-like contexts, few have attempted to operationalize the communication styles leaders use in their daily transactions with subordinates. Even fewer have attempted to find out what the relations are of these communication styles with general leadership styles and outcome variables. This is somewhat surprising, given that one of the core elements of leadership is a leader's interpersonal communication style. In this 
study, we will consider leadership from this communicative perspective, and we will define a leader's communication style as a distinctive set of interpersonal communicative behaviors geared toward the optimization of hierarchical relationships in order to reach certain group or individual goals. In line with Daft (2003) and McCartney and Campbell (2006), we make a distinction between the interpersonal aspects of leadership, which revolve around communicative activities in interpersonal relationships, and the managerial aspects of leadership, which revolve around non-interpersonal activities such as planning, organizing, decision-making, problem-solving, and controlling, and we will focus our work on the first of these two, i.e., a leader's interpersonal communicative behaviors. The goal of this paper is to operationalize a leader's interpersonal communication style, to uncover the relations between common leadership style measures and our measure of a leader's communication style, and to find out about the differential and incremental prediction of several important leadership outcomes using both common leadership style measures and our leader's communication style measure.

\section{The Nature of Communication Styles}

Although there are a great number of instruments to measure somebody's interpersonal communication style, several authors have noted the lack of parsimony and integration in the burgeoning area of communication style studies (McCroskey et al. 1998). Several authors have attempted to redress this state of affairs by integrating diverse communication style scales with the interpersonal circumplex model (Leary 1957), which consists of the following two main interpersonal (communicative) dimensions: friendliness/affiliation and dominance (Dillard et al. 1999; Hansford and Hattie 1987; Sorenson and Savage 1989). Others have suggested that there are more than two communication style dimensions. For instance, Gudykunst et al. (1996) factor-analyzed 96 items from existing communication style instruments (Booth Butterfield and Booth Butterfield 1990; Norton 1978; Singelis 1994; Takai and Ota 1994; Wiemann et al. 1986) and 62 additional items based on Hall's (1976) and Gudykunst and Ting Toomey (1988) conceptualization of low- and highcontext communication, and arrived at eight factors: Inferring Meaning, Indirect Communication, Interpersonal Sensitivity, Dramatic Communication, Use of Feelings, Openness, Preciseness, Positive Perception of Silence. However, according to De Vries et al. (2009), some of the scales based on these factors (e.g., Inferring Meaning, Use of Feelings, and Positive Perception of Silence) do not pertain to interpersonal communication styles, but to intrapersonal cognitions and feelings with respect to communication, and consequently may be less useful in assessment situations or in cases in which an observer (e.g., a subordinate) has to rate somebody else's (e.g., a leader's) interpersonal communication style.

To arrive at a framework of communication styles, De Vries et al. (2009) carried out a lexical study to uncover the main communication style dimensions. The basis of a lexical study is the idea that anything which can be said about a construct, such as somebody's communication style, will become encoded in language (Galton 1884; Goldberg 1990). Factor-analysis of a sample of all dictionary words which pertain to communication should provide the best description of the nature, number, and size of the principal communication style dimensions. Having carried out a lexical study using 744 adjectives and 837 verbs, De Vries et al. (2009) arrived at seven main communication style dimensions, which they labelled: Expressiveness, Preciseness, Niceness, Supportiveness, Verbal Aggressiveness, (Expressed) Emotional Tension (or, reversed, Assuredness), and Argumentativeness. Regression of the Communication Style Scale (CSS) of Gudykunst et al. (1996) on the lexical communication factors revealed strong correspondence between $\mathrm{Gu}-$ dykunst et al.'s Openness and Dramatic Communication on the one hand and lexical Expressiveness on the other, $\mathrm{Gu}-$ dykunst et al.'s Preciseness and lexical Preciseness, and Gudykunst et al.'s Interpersonal Sensitivity and lexical Niceness. The so-called intrapersonal communication scales of Gudykunst et al. (1996) were less well covered by the lexical scales. Conversely, lexical (Expressed) Emotional Tension, Verbal Aggressiveness, and Argumentativeness were less represented in Gudykunst et al.'s scales.

\section{Outcomes Associated with Communication Styles}

Although it appears that there are more than two main communication style dimensions, until now, when investigating communication styles, most scholars have focused on the two styles that are most closely associated with the interpersonal circumplex, i.e., friendliness and dominance. Communication styles have been an especially welcome topic for scholars interested in doctor-patient communication (Bultman and Svarstad 2000; Hailey et al. 1998; Street 2002; Van Dulmen and Bensing 2002; Yedidia et al. 2003), teacher-pupil communication (Noels et al. 1999; Prisbell 1994), parent-child communication (Bugental et al. 1999; Hawes 1996; Ritchie and Fitzpatrick 1990), and communication among married or dating couples (Bienvenu 1970; Christensen 1988; Noller and White 1990).

Results of doctor-patient studies suggest that especially a supportive (i.e., friendly and caring) communication style is associated with higher satisfaction among patients (Buller and Buller 1987; Schmid Mast et al. 2007), while a dominant style is associated with less satisfaction among patients and less favorable outcomes, such as malpractice 
claims (Ambady et al. 2002; Buller and Buller 1987; Burgoon et al. 1987; Levinson et al. 1997). Results of classroom studies suggest that a supportive communication style is associated with greater satisfaction among students (Prisbell 1994) and that a dominant (controlling) communication style is associated with less intrinsic motivation (Noels et al. 1999). In the family setting, however, children were found to be more attentive and task-oriented when parents used an unambiguous and dominant communication style (Bugental et al. 1999; Rasku Puttonen 1988).

The above studies seem to indicate that satisfaction is more often associated with a friendly communication style, while a dominant communication style may be associated with performance, but only in some instances (e.g., strong dependence situations). One important intermediate concept, which may be determined by communication styles on the one hand, and which determines team performance (Srivastava et al. 2006) and may determine satisfaction, is the concept of knowledge sharing. Knowledge sharing has been defined as the process where individuals mutually exchange their (tacit and explicit) knowledge and jointly create new knowledge (Van den Hooff and De Ridder 2004). Knowledge sharing may be an interesting variable in relation to communication styles, because the exchange process assumes a communication process. Even when people have ready access to the internet or a firm's intranet, people are more likely to turn to other people for information than to impersonal sources (Levin and Cross 2004). Consequently, the communication style of a team member is likely to have an effect on the willingness and eagerness of team members to share knowledge with each other. In a study by De Vries et al. (2006), team members were found to be more likely to be willing to share knowledge with team members who were more agreeable and extraverted in their communication style. Consequently, not only satisfaction is likely to be affected by the communication style of a communication partner, but also the likelihood that one shares knowledge with a communication partner.

\section{Leaders' Communication Styles}

The question is: are the findings of the communication style literature replicable in the leadership context? The leadership style literature may be characterized by referring to two main phases: approximately 30 years of studying leader consideration and initiating structure from 1953 until the middle of the 1980s and approximately 25 years of studying charismatic-transformational leadership from the middle of the 1980s until the present. Studies on leaders' communication styles have kept up with this shift in focus. In a review of the relations between interpersonal communication behaviors and leadership consideration and initiating structure, Penley and Hawkins (1985) conclude that consideration (or: human-oriented leadership) is mainly communicative, while initiating structure (or: taskoriented leadership) is much less so. According to Penley and Hawkins (1985), the close correspondence between human-oriented leadership and communication is due to the fact that consideration is heavily saturated with relational aspects of communication, such as interpersonal concern and warmth, while task-oriented leadership is much more saturated with the actual content of the information provided instead of the style of communication.

Given the explosion of studies on charismatic-transformational leadership, it is surprising that the number of studies linking communication to charismatic-transformational leadership is relatively sparse and directed mostly at oratory skills and content (Awamleh and Gardner 1999; Den Hartog and Verburg 1997; Frese et al. 2003; Kirkpatrick and Locke 1996; Riggio et al. 2003; Shamir et al. 1994; Spangler and House 1991; Towler 2003). For instance, with respect to communication styles, charismatic leadership training studies have looked at the effects of training inspirational delivery style on the trainees and their public (Frese et al. 2003; Towler 2003), showing positive effects of the training on the trainees and on the attitudes and performance of their public. An experimental study by Awamleh and Gardner (1999) focused on the effects of vision content and delivery style on perceptions of charismatic leadership and effectiveness. The study showed that an expressive (enthusiastic) delivery style had a much stronger effect than the content of the speech. Because charismatic leadership has been found to be strongly related to human-oriented leadership (De Vries et al. 2002) and because human-oriented and charismatic leadership are much more saturated with relational content than taskoriented leadership, we propose the following hypothesis:

Hypothesis 1 Communication styles are more strongly related to charismatic and human-oriented leadership than to task-oriented leadership.

We do expect, however, the determinants of charismatic leadership and human-oriented leadership to be different. While human-oriented leadership will be mainly determined by a supportive communication style, charismatic leadership will be determined by all communication styles that have a positive connotation, i.e., expressiveness, preciseness, assuredness, supportiveness, argumentativeness, and a lack of verbal aggressiveness.

Leadership, Communication Styles, and Outcomes

The literature on communication styles and outcomes and on communication styles and leadership styles implies that 
communication styles are meaningfully related to a number of outcome variables and to some, but not all, leadership styles. The question is whether communication styles of a leader are similarly related to outcome variables as the traditional leadership styles. In comparison with the communication styles literature, there has been an abundance of studies associating outcomes with charismatic, humanoriented, and task-oriented leadership. To combine these studies, several meta-analyses have been conducted to investigate the relations between leadership styles and both organizational and individual outcomes (DeGroot et al. 2000; Fuller et al. 1996; Judge and Piccolo 2004; Lowe et al. 1996; Stewart 2006). For instance, the meta-analysis of Judge and Piccolo (2004) revealed positive relations between both transformational and charismatic leadership and subordinates' job satisfaction, satisfaction with the leader, motivation, leader effectiveness, and group performance. Judge and Piccolo (2004) did not find any significant differences in results between charismatic and transformational leadership, which shows that these constructs are by-and-large interchangeable. A meta-analysis on leader's consideration (e.g., human-oriented leadership) and initiating structure (e.g., task-oriented leadership) also revealed positive effects on outcomes for these two styles (Judge et al. 2004). Most notable, leader's consideration was more strongly related to subordinates' job satisfaction, satisfaction with the leader, and leader effectiveness than initiating structure.

Lately, there has been an increased interest in the predictors of knowledge sharing. (De Vries et al. 2006; Srivastava et al. 2006). Especially leadership may play a central role in inspiring and supporting knowledge sharing behaviors. Consequently, both charismatic and humanoriented leadership are likely to have a positive effect on both knowledge collecting and donating behaviors. Srivastava et al. (2006) looked at the relation between empowering leadership and knowledge sharing. Encouragement of self-management, a concept akin to empowering leadership, has been found to be very strongly related to human-oriented and charismatic leadership (De Vries et al. 2002). Srivastava et al. (2006) found a positive relation of empowering leadership on knowledge sharing, which suggests that both human-oriented and charismatic leadership will be related to knowledge sharing.

The question is: To what degree do these results reflect the relation of communication styles with these outcomes. According to the literature on communication styles (see above), we may expect to find significant relations with satisfaction. In line with the study on team communication styles and outcomes (De Vries et al. 2006) there may also be significant relations with knowledge sharing. Consequently, in general, we expect the communication styles to be significantly related to the outcomes in this study. Based on the notion that especially charismatic leadership and human-oriented leadership represent communication styles, we propose the following hypothesis:

Hypothesis 2 Both the communication styles and the charismatic and human-oriented leadership styles explain a significant amount of variance in perceived leader performance, satisfaction with the leader, subordinates' commitment, and both donating and collecting knowledge sharing of a subordinate with his/her leader.

Note that we expect charismatic and human-oriented leadership to be positively related to these outcomes. Again, as noted in hypothesis 1, we expect the effects of a supportive communication style to resemble the effects of human-oriented leadership. However, because we expect charismatic leadership to be characterized by a profile of high scores on expressiveness, preciseness, supportiveness, assuredness, and argumentativeness, and low scores on verbal aggressiveness, these communication styles will tend to correlate with the outcome variables which are related to charismatic leadership.

The last hypothesis concerns the direction of the effects we propose for this study. Several authors have noted that attributional processes play a key role in leadership ratings. Conger and Kanungo (1988, p. 79) note, for instance, that "charismatic leadership is an attribution based on follower's perceptions of their leader's behavior." One of the most important attributional processes is a recognitionbased process (Lord and Maher 1993). Recognition-based processes involve the perception of leadership behaviors on the one hand and the matching of these behaviors with relevant implicit leadership theories on the other hand. Implicit leadership theories seem to be to a large extent culturally universal (Den Hartog et al. 1999), and thus, of these two subprocesses (i.e., behavior perception and matching using an implicit leadership theory), the perception process of actual observable behaviors seems to be most important in the judgment of a person's leadership style.

An example of the influence of observable communication behaviors on the perception of leadership is a study by Naidoo and Lord (2008) on the relation between leader speech imagery and followers perceptions of charismatic leadership. Use of speech imagery, which links to sensory experiences, was positively associated with ratings of charismatic leadership. In a similar vein, Awamleh and Gardner (1999) found both communication content and delivery style to be positively related to perceptions of charisma and perceived leader effectiveness. This study's communication styles reflect more observable behaviors (i.e., all items pertain to communication acts) than the leadership styles, which contain attributional—not directly observable-elements (e.g., "My leader trusts his/her 
subordinates" for human-oriented leadership ${ }^{1}$ and "My leader has a vision and image of the future" for charismatic leadership). Consequently, we believe attributed humanoriented leadership and charismatic leadership to be mediators of the relation between the communication styles and the outcomes in this study and thus we propose the additional third hypothesis:

Hypothesis 3 Charismatic and human-oriented leadership mediate the relations between the communication styles of a leader and the outcomes of this study, i.e., perceived leader performance, satisfaction with the leader, subordinates' commitment, and both donating and collecting knowledge sharing.

The advantage of this study's model, which links communication styles to leadership, is that models based on personality traits, which can be considered to be the primary determinants of leadership styles, predominantly either omit the most central feature of leadership, i.e., interpersonal communication, or do not capture it adequately. Although studies have shown that personality traits are related to leadership (De Hoogh et al. 2005; Judge and Bono 2000; Lord et al. 1986), it is doubtful whether the questions used in standard personality research, such as pertaining to eating, movie watching, or holiday habits (all taken from the NEO-PI-R, Costa and McCrae 1992), are able to capture the behaviors exhibited in leader-subordinate interactions. Although communicative behaviors can be regarded as a subset of personality, what exactly constitutes this subset has not been properly investigated until recently (De Vries et al. 2009). By relying on a measure derived from lexical research, this study will be able to more adequately capture somebody's communication style in general and a leader's communication style in particular, and to explore the links with several important outcomes.

\section{Method}

\section{Participants}

A survey was distributed to the employees of the Dutch Ministry of Education, Culture and Science. The Ministry was in the process of assessing the organizational culture, and investigating the leadership and communication styles of leaders was part of the overall research. Of 279 respondents $52.0 \%$ was male and $16.7 \%$ of the participants occupied a leadership position. Participants indicated that

\footnotetext{
${ }^{1}$ Note that several authors (e.g., Eden and Leviatan 1975; Rush et al. 1977) have shown that ratings on consideration (Fleishman 1953), on which human-oriented leadership is based (see De Vries et al. 2002), are also brought about by a recognition-based attributional process.
}

$65.8 \%$ of their supervisors was male. The age of the participants who completed the survey ranged from 20 to 65 with a median of 44 years; $64.3 \%$ completed a university education.

\section{Instruments}

A computerized survey was used, consisting of 16 background questions and 138 items. The items were selected from existing questionnaires. Answers were provided on a five-point (disagree-agree) scale. For measuring task- and human-oriented leadership styles, the short version of Syroit's (1979; De Vries et al. 2002) Dutch translation of the Supervisory Behavior Description Questionnaire (SBDQ; Fleishman 1953) was used. For measuring the charismatic leadership style a short Dutch version of Bass' (1985) Multifactor Leadership Questionnaire (De Hoogh et al. 2004; Den Hartog et al. 1997) was used. In previous studies, these scales have consistently shown strong reliabilities, i.e., .84 for task-oriented leadership, .92 for human-oriented leadership, and .88 for charismatic leadership (De Hoogh et al. 2004; De Vries et al. 2002). In the current research Cronbach's alphas were .86 for task-oriented leadership, .91 for human-oriented leadership, and .90 for charismatic leadership.

The questionnaire which measured a leader's interpersonal communication style was based on the outcomes of a lexical study, which identified seven main communication dimensions (for a detailed explanation of this study: see De Vries et al. 2009). To measure these seven dimensions, 87 items, representing each of the poles of the seven dimensions, were written. A Principal Axis Factoring (PAF) analysis with varimax rotation was conducted. Based on the scree plot and the content of the items we identified six factors, which explained a total of $56.3 \%$ of the variance. No reliable scales could be constructed from additional factors. ${ }^{2}$ The following names were given to the scales constructed by summing the highest loading items of these six dimensions: leader's verbal aggressiveness ( 10 items, in the current study $\alpha=.92$ ), expressiveness (10 items, $\alpha=.89$ ), preciseness (10 items, $\alpha=.90$ ), assuredness (10 items, $\alpha=.81$ ), supportiveness (9 items, $\alpha=.89$ ), and argumentativeness ( 4 items, $\alpha=.68$ ). Five of the 15 possible correlations between the communication scales were above the .40 level; e.g., supportiveness correlated -.57 with verbal aggressiveness and .54 with expressiveness (see Table 1). Examples of items of the communication style scales were: "If things don't work out, my leader becomes very angry" (verbal aggressiveness), "My leader

\footnotetext{
2 A full description of the Principal Axis Factoring analysis can be obtained from the first author.
} 


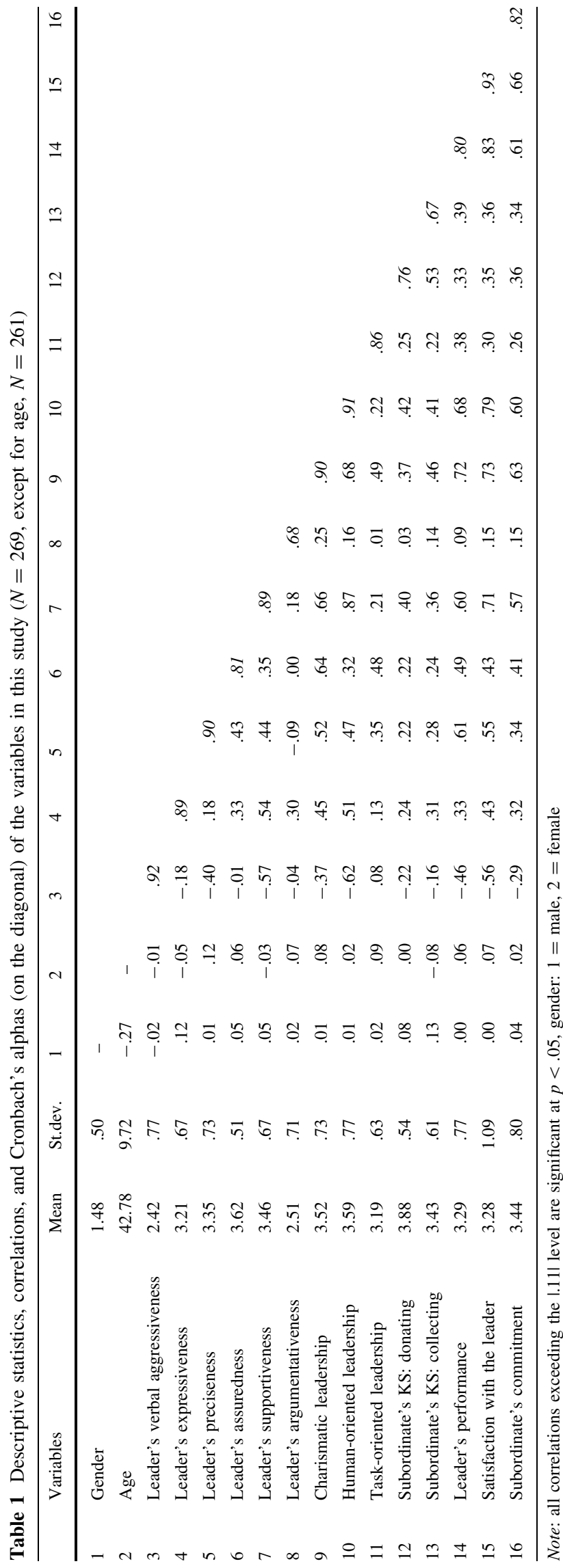

often tells a lively story" (expressiveness), "My leader expresses him-/herself in a concise manner" (preciseness), "Often, my leader lets others resolutely know what s/he thinks" (assuredness), "My leader often gives somebody a compliment" (supportiveness), and "My leader likes to analyze everything" (argumentativeness).

We measured the following leadership outcomes: knowledge donating and collecting, perceived leader performance, satisfaction with the leader, and subordinate's team commitment. To measure knowledge donating and collecting behaviors the questionnaire of Van den Hooff and Hendrix (2004; see also De Vries et al. 2006) was used. The items were adapted to reflect a subordinate's knowledge sharing behavior with his/ her supervisor. Cronbach's alphas in De Vries et al.'s (2006) study were 84 for Donating Knowledge Sharing and .75 for Collecting Knowledge Sharing. In this study, the Cronbach's alphas were .76 and .67 , respectively. To measure subordinate's perception of leader performance and their satisfaction with the leader two scales were constructed, each consisting of four items. An example of a leader performance item is: "My superior is not very efficient." An example of a reverse coded item to measure satisfaction with the leader is: "I sometimes think: 'I wish I had another superior" ". The Cronbach's alphas for these scales were .80 and .93 , respectively. To measure employee commitment the short version of the Dutch translation of Allen and Meyer's (1990) questionnaire was used (De Gilder et al. 1997); in this study the Cronbach's alpha was .82 .

Analyses

First of all, we checked the data to assess deviant answering patterns. We calculated the within-person mean and standard deviation for all variables in the study. We visually checked the answers for those cases in which the within-person mean was $>4.5$ or $<1.5$ or the standard deviation was close to 0 . We decided to exclude 10 cases from further analyses. Apart from Pearson's correlations, we used multiple regression analyses to inspect the relations between the leader communication styles, leadership styles, and leadership outcomes. Based on the multiple regression analysis, we checked whether, statistically, ${ }^{3}$ mediation occurred in the relation between the leader

\footnotetext{
${ }^{3}$ Note that we will use the term 'statistical mediation' to distinguish it from 'causal' mediation which, some argue, only occurs when two or more randomized experiments are conducted (see Stone-Romero and Rosopa (2008)—but also see James (2008) and Kenny (2008) for a rebuttal).
} 
communication styles and leadership styles on the one hand and the leadership outcomes on the other using the procedure advocated by Baron and Kenny (1986). Thus, we checked: (1) whether the communication styles were significantly related to the outcome variables, (2) whether the communication styles were significantly related to the proposed mediators (the leadership styles), and (3) whether the mediators were significantly related to the outcome variables. When mediation occurred, we conducted additional analyses using separate variables (i.e., one independent variable, one dependent variable, and one mediator) to establish the nature and significance of the mediation effect (Mathieu and Taylor 2006; Sobel 1982). A leadership style fully mediated the relation between the communication style and the outcome variables if the relation between the communication style and leadership outcome after controlling for the leadership style was no longer significant (Baron and Kenny 1986). If the relation between the communication style and leadership outcome was still significant, but less strong, partial mediation occurred.

\section{Results}

The correlations between the variables in this study are reported in Table 1 . Gender and age were unrelated to the rest of the variables in this study, except for two minor, but significant, correlations between gender and both leader expressiveness $(r=.12, \quad p=.05)$ and subordinate's knowledge collecting ( $r=.13, p=.03$ ). Female subordinates rated their leader slightly higher on expressiveness and reported slightly more knowledge collecting than male subordinates.

Table 1 reveals several strong correlations between the communication styles of a leader and his/her leadership style. The two strongest correlates of charismatic leadership were leader's supportiveness $(r=.66, p<.01)$ and leader's assuredness $(r=.64, p<.01)$. The two strongest correlates of human-oriented leadership were again leader's supportiveness $(r=.87, p<.01)$ and leader's verbal aggressiveness $(r=-.62, p<.01)$. The relations of the communication styles of a leader with task-oriented leadership were less strong, but still significant, with the two strongest correlates leader's assuredness $(r=.48, p<.01)$ and leader's preciseness $(r=.35, p<.01)$. Note that verbal aggressiveness had a strong negative correlation with human-oriented leadership and a medium-sized negative one with charismatic leadership, but a small (but not significant) positive correlation with task-oriented leadership. Of all communication variables, leader's argumentativeness was the weakest correlate of all three leadership styles.

With respect to the outcome variables in this study, the main communication style correlate of the outcomes was leader's supportiveness, with correlations varying between .36 for subordinate's knowledge collecting and .71 for satisfaction with the leader. One exception was the correlation between leader's preciseness and perceived leader's performance $(r=.61, p<.01)$, which was just slightly higher than the correlation between leader's supportiveness and perceived leader's performance $(r=.60, p<.01)$. Leader's verbal aggressiveness correlated negatively with all outcomes. The lowest correlations between the communication styles and the outcomes were for leader's argumentativeness, with correlations ranging between .03 (for subordinate's knowledge donating behaviors) and .15 (for both satisfaction with the leader and subordinate's team commitment). Charismatic and human-oriented leadership correlated even stronger with perceived leader's performance, satisfaction with the leader, and subordinate's commitment than leader's supportiveness and had similar-sized correlations with the two knowledge sharing behavior variables; all of these correlations were stronger than the correlations involving task-oriented leadership.

In Table 2 the regression analyses of the leadership styles on the communication style variables are reported. Apart from the standardized beta coefficients, we also report the semi-partial $r^{2}$ s, which can be interpreted as the incremental variance of each of the communication style variables separately. Charismatic leadership was significantly related to five of the six communication style variables. Somewhat surprisingly, leader's expressiveness did not explain any incremental variance in charismatic leadership, while all other communication style variables did. The two strongest predictors of charismatic leadership were leader's assuredness $(\beta=.45, p<.01)$ and leader's supportiveness $(\beta=.34, p<.01)$. In line with expectations, human-oriented leadership was strongly associated with leader's supportiveness $(\beta=.67, p<.01)$; the two other significant regression coefficients, although much less strong, involved verbal aggressiveness $(\beta=-.19$, $p<.05)$ and expressiveness $(\beta=.09, p<.05)$. Compared to charismatic leadership and human-oriented leadership, the relations between the communication styles and taskoriented leadership were less strong; the two strongest correlations were between task-oriented leadership and leader's assuredness $(\beta=.34, \quad p<.01)$ and verbal aggressiveness $(\beta=.27, p<.01)$. Note that the relation between task-oriented leadership and leader's verbal aggressiveness was opposite to the relations of leader's verbal aggressiveness with charismatic and human-oriented leadership.

The communication styles explained more variance in charismatic leadership $\left(R^{2}=.69, p<.01\right)$ and humanoriented leadership $\left(R^{2}=.79, p<.01\right)$ than in task-oriented leadership $\left(R^{2}=.30, p<.01\right)$. A test of the difference of dependent multiple $R$ 's, after conversion to 
Table 2 Multiple regression of charismatic, human-oriented, and task-oriented leadership on leader's communication styles $(N=269)$

\begin{tabular}{|c|c|c|c|c|c|c|}
\hline & \multicolumn{2}{|c|}{$\begin{array}{l}\text { Charismatic } \\
\text { leadership }\end{array}$} & \multicolumn{2}{|c|}{$\begin{array}{l}\text { Human-oriented } \\
\text { leadership }\end{array}$} & \multicolumn{2}{|c|}{$\begin{array}{l}\text { Task-oriented } \\
\text { leadership }\end{array}$} \\
\hline & $\beta$ & Semi-partial $r^{2}$ & $\beta$ & Semi-partial $r^{2}$ & $\beta$ & Semi-partial $r^{2}$ \\
\hline Leader's verbal aggressiveness & $-.10^{*}$ & .00 & $-.19 *$ & .02 & $.27 * *$ & .04 \\
\hline Leader's expressiveness & .02 & .00 & $.09 *$ & .01 & -.09 & .00 \\
\hline Leader's preciseness & $.15^{* *}$ & .01 & .08 & .00 & $.25^{* *}$ & .04 \\
\hline Leader's assuredness & $.45^{* *}$ & .13 & .02 & .00 & $.34 * *$ & .08 \\
\hline Leader's supportiveness & $.34 * *$ & .05 & $.67 * *$ & .19 & $.17 *$ & .01 \\
\hline Leader's argumentativeness & $.19 * *$ & .03 & .01 & .00 & .04 & .00 \\
\hline Multiple $R$ & $.83 * *$ & & $.89 * *$ & & $.55^{* *}$ & \\
\hline
\end{tabular}

$* p<.05 ; * * p<.01$

Z-scores, revealed a significant difference between the communication styles_charismatic leadership multiple $R$ and the communication styles-task-oriented leadership multiple $R(z=5.72, p<.01)$ and between the communication styles - human-oriented leadership multiple $R$ and the communication styles-task-oriented leadership multiple $R(z=8.84, p<.01)$. These results offer support for hypothesis 1 . Additionally, we checked whether the profiles of beta's of the communication styles differed significantly in the three regression analyses reported in Table $2 .^{4}$ All three of the contrasts proved to be significantly different, that is, the communication styles had a different profile of beta's when comparing the profile of charismatic leadership with the profile of human-oriented leadership $(F=28,25, p<.01)$, when comparing the profile of charismatic leadership with the profile of taskoriented leadership $(F=19,61, p<.01)$, and when comparing the profile of human-oriented leadership with the profile of task-oriented leadership $(F=40,86, p<.01)$. The results show that not only do the leadership styles differ in the extent to which communication styles in general play a role in the perception of leadership, but also in the extent to which different communication styles play a role.

To test hypothesis 2, i.e., the relations between the leadership styles and communication styles on the one hand, and the outcome variables on the other, we conducted multiple regression analyses with each of the outcome variables. In Table 3 the multiple regression analyses of the knowledge sharing behaviors are reported; Table 4 reports the multiple regression analyses involving perceived leader performance, satisfaction with the leader, and subordinate's team commitment. The first column of the outcome variables in the tables pertains to the relations of the communication styles to the outcome variables, the second one involves the leadership styles, and the third

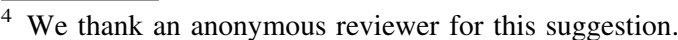

column contains all of the variables together. The results in the first columns show that the communication style variables explained a significant amount of variance in all of the outcome variables with multiple $R$ 's ranging from .41 for knowledge donating behaviors to .80 for satisfaction with the leader. The multiple $R$ 's involving the leadership styles were almost similar to the ones involving the communication styles, ranging from .46 for knowledge donating behaviors to .83 for satisfaction with the leader. Of the communication style variables, leader's supportiveness was the strongest statistical predictor of knowledge donating behaviors. Of the leadership style variables, human-oriented leadership was the strongest statistical predictor of knowledge donating behaviors, but task-oriented leadership also explained incremental variance in knowledge donating behaviors. The main communication style predictors of knowledge collecting behaviors were leader's supportiveness, leader's preciseness, and leader's expressiveness, ${ }^{5}$ while the main leadership style predictors of knowledge collecting behaviors were charismatic leadership and human-oriented leadership.

Of the outcome variables reported in Table 4, except for leader's expressiveness, all communication style variables were significantly related to perceived leader performance and satisfaction with the leader. For subordinate's team commitment, this was only true for leader's supportiveness and leader's assuredness. Of the leadership style variables, charismatic leadership and human-oriented leadership had positive significant relations with all three outcomes in Table 4. Task-oriented leadership only had a positive significant relation with perceived leader performance. These

\footnotetext{
${ }^{5}$ However, because gender was significantly related to both leader's expressiveness and knowledge collecting behaviors, we reran the analysis with gender as a control variable. The relation of leader's expressiveness with knowledge collection, which was marginally significant $(r=.14, p=.05)$ in the first place, turned to be nonsignificant with gender in the equation $(r=.13, p=.08)$. No other changes in the regression coefficients were observed.
} 
Table 3 Multiple regression of knowledge sharing on leader's communication styles (LCS) and leadership styles (LS) $(N=269)$

\begin{tabular}{|c|c|c|c|c|c|c|}
\hline & \multicolumn{3}{|c|}{ Knowledge sharing: } & \multicolumn{3}{|c|}{ Knowledge sharing: } \\
\hline & \multicolumn{3}{|c|}{ Donating behaviors } & \multicolumn{3}{|c|}{ Collecting behaviors } \\
\hline & LCS $\beta$ 's & LS $\beta$ 's & All $\beta$ 's & LCS $\beta$ 's & LS $\beta$ 's & All $\beta$ 's \\
\hline Leader's verbal aggressiveness & .00 & & .02 & .06 & & .14 \\
\hline Leader's expressiveness & .03 & & .02 & $.14 *$ & & .11 \\
\hline Leader's preciseness & .02 & & -.05 & $.17^{*}$ & & .10 \\
\hline Leader's assuredness & .08 & & -.01 & .05 & & -.13 \\
\hline Leader's supportiveness & $.35^{* *}$ & & .11 & $.21 *$ & & -.08 \\
\hline Leader's argumentativeness & -.04 & & -.06 & .08 & & .00 \\
\hline Charismatic leadership & & .06 & .08 & & $.33 * *$ & $.38 * *$ \\
\hline Human-oriented leadership & & $.35^{* *}$ & $.28 *$ & & $.18^{*}$ & .24 \\
\hline Task-oriented leadership & & $.14 *$ & $.14^{*}$ & & .01 & -.01 \\
\hline Multiple $R$ & $.41 * *$ & $.46^{* *}$ & $.46^{* *}$ & $.43 * *$ & $.48 * *$ & $.50^{* * *}$ \\
\hline
\end{tabular}

$* p<.05 ; * * p<.01$

Table 4 Multiple regression of leadership outcomes on leader's communication styles (LCS) and leadership styles (LS) $(N=269)$

\begin{tabular}{|c|c|c|c|c|c|c|c|c|c|}
\hline & \multicolumn{3}{|c|}{ Perceived leader performance } & \multicolumn{3}{|c|}{ Satisfaction with the leader } & \multicolumn{3}{|c|}{ Subordinate's team commitment } \\
\hline & LCS $\beta$ 's & LS $\beta$ 's & All $\beta$ 's & LCS $\beta$ 's & LS $\beta$ 's & All $\beta$ 's & LCS $\beta$ 's & LS $\beta$ 's & All $\beta$ 's \\
\hline Leader's verbal aggressiveness & $-.18 * *$ & & -.09 & $-.26^{* *}$ & & $-.15^{* *}$ & -.01 & & .11 \\
\hline Leader's expressiveness & -.01 & & -.04 & .06 & & .02 & -.05 & & -.09 \\
\hline Leader's preciseness & $.32 * *$ & & $.23^{* *}$ & $.20 * *$ & & $.12 * *$ & .05 & & -.02 \\
\hline Leader's assuredness & $.26^{* *}$ & & .09 & $.20 * *$ & & .06 & $.24 * *$ & & .08 \\
\hline Leader's supportiveness & $.27 * *$ & & -.08 & $.36^{* *}$ & & -.04 & $.47 * *$ & & .10 \\
\hline Leader's argumentativeness & .06 & & .00 & $.07 *$ & & .02 & .08 & & .01 \\
\hline Charismatic leadership & & $.42 * *$ & $.32 * *$ & & $.36^{* *}$ & $.27 * *$ & & $.41 * *$ & $.37 * *$ \\
\hline Human-oriented leadership & & $.37 * *$ & $.34 * *$ & & $.55^{* *}$ & $.45^{* *}$ & & $.32 * *$ & $.37 * *$ \\
\hline Task-oriented leadership & & $.09 *$ & .05 & & .00 & -.01 & & -.01 & -.06 \\
\hline Multiple $R$ & $.75 * *$ & $.77 * *$ & $.80 * *$ & $.80 * *$ & $.83 * *$ & $.85^{* *}$ & $.62 * *$ & $.67 * *$ & $.68 * *$ \\
\hline
\end{tabular}

$* p<.05 ; * * p<.01$

results support hypothesis 2 , i.e., both the communication styles and the charismatic and human-oriented leadership styles explain a significant amount of variance in all of the outcome variables.

The third column of each outcome variable in Tables 3 and 4 reports the multiple regression of all communication and leadership style variables combined. In conjunction with Tables 1 and 2 and the first two columns of each outcome variable in Tables 3 and 4, it shows that the leadership styles statistically mediated the relations between the communication styles on the one hand and the outcome variables on the other. With respect to knowledge donating and collecting behaviors (Table 3), none of the regression coefficients of the communication style variables remained significant when the leadership style variables were entered as well. Additional analyses, leaving out task-oriented leadership and humanoriented leadership separately in the regression equation, showed that this effect was entirely due to human-oriented leadership. When only charismatic leadership and task-oriented leadership were entered in the regression equation together with the communication styles, leader's supportiveness was still significantly related to knowledge donating behaviors $(\beta=.28, p<.01)$, while this was not true when leader's supportiveness was entered in the regression equation together with charismatic leadership and human-oriented leadership ( $\beta=.11, p<.37$ ). A mediation analyses based on Mathieu and Taylor's (2006) decision tree, which helps to distinguish between indirect effects, full mediation effects, and partial mediation effects, showed that human-oriented leadership fully statistically mediated the relation between leader's supportiveness and knowledge donating behaviors. A Sobel (1982) test indicated a significant indirect effect of leader's supportiveness on knowledge donating behaviors through human-oriented leadership $(z=7.31, p<.01)$.

Table 3 also shows that charismatic leadership statistically mediated the relations between leader's supportiveness, 
leader's preciseness, and leader's expressiveness on the one hand and knowledge collecting behaviors on the other. Separate mediation tests (and Sobel indirect effect tests) showed that the relation between knowledge collecting behaviors and leader's expressiveness was partially statistically mediated by charismatic leadership (with a significant indirect effect; $z=5.88, p<.01$ ), while the relations between knowledge collecting behaviors and both leader's preciseness and leader's supportiveness were fully statistically mediated by charismatic leadership (with significant indirect effects; respectively, $z=6.41, p<.01$ and $z=7.24, p<.01$ ).

Statistical mediation was also shown when perceived leader performance, satisfaction with the leader, and subordinate's team commitment were the outcome variables. For perceived leader performance and satisfaction with the leader, only partial statistical mediation was found. Leader's preciseness explained incremental variance in perceived leader performance when entered together with charismatic leadership and human-oriented leadership and both leader's preciseness and leader's verbal aggressiveness explained incremental variance in satisfaction with the leader when entered together with charismatic leadership and human-oriented leadership. Except for the relation between leader's preciseness and perceived leader performance and except for the relations between leader's preciseness and verbal aggressiveness and satisfaction with the leader, the results offer support for Hypothesis 3. Further mediation analyses using the separate variables based on Mathieu and Taylor's (2006) decision tree showed that human-oriented leadership, but not charismatic leadership, ${ }^{6}$ fully statistically mediated the relations between leader's verbal aggressiveness and leader's supportiveness on the one hand and perceived leader performance on the other (with significant indirect effects; respectively, $z=9.82$, $p<.01$ and $z=13.25, p<.01$ ), while charismatic leadership, but not human-oriented leadership, fully statistically mediated the relation between leader's assuredness and perceived leader performance (with a significant indirect effect; $z=10.54, p<.01$ ).

Similar results were found for satisfaction with the leader and subordinate's team commitment. Human-oriented leadership, but not charismatic leadership, fully statistically mediated the relations between leader's supportiveness on the one hand and satisfaction with the leader and subordinate's team commitment on the other (with significant indirect effects; respectively, $z=16.86$, $p<.01$ and $z=11.25, p<.01$ ), while charismatic leadership, but not human-oriented leadership, fully statistically mediated the relation between leader's assuredness and satisfaction with the leader (with a significant indirect

\footnotetext{
${ }^{6}$ In this case (and subsequent cases), partial mediation occurred.
}

effect; $z=10.69, p<.01)$. However, human-oriented leadership also fully statistically mediated the relation between leader's assuredness and subordinate's team commitment (with a significant indirect effect; $z=5.01$, $p<.01)$.

\section{Conclusions and Discussion}

According to Yukl (1999), there is a 'considerable ambiguity about the essential behaviors for charismatic and transformational leadership' (p. 301), and conceptual weaknesses in charismatic and transformational leadership are 'similar to those in most of the earlier leadership theories' (p. 286). This study has tried to clarify the essential ingredients of charismatic and human-oriented leadership. According to this research, both charismatic and humanoriented leadership styles are to a considerable extent grounded in communication styles. In contrast, task-oriented leadership is much less communicative and may be regarded, following Daft (2003) and McCartney and Campbell (2006), more as a managerial than as a leadership style. Consequently, the question whether leadership $=$ communication can be answered in the affirmative for charismatic and human-oriented leadership and is disconfirmed for task-oriented leadership.

There are several noteworthy findings in this study. First of all, charismatic leadership and human-oriented leadership are characterized by a different communication style profile. Human-oriented leadership is strongly associated with the communication style supportiveness, and to a lesser extent with leader's expressiveness and (a lack of) leader's verbal aggressiveness. In contrast, charismatic leadership is characterized by a profile which includes five out of the six communication styles. Charismatic leaders are characterized by an assured, supportive, argumentative, precise, and verbally non-aggressive communication style. Surprisingly, expressiveness was found to be unrelated to charismatic leadership when entered in the regression equation together with the other communication styles. On the one hand, it may be true that charismatic leaders do not need to be particularly expressive to reach their desired effect, as for instance less expressive but notable charismatic leaders, such as Mahatma Gandhi, have shown. On the other hand, cultural 'styles' may play a role, with subjects from the Netherlands valuing a less 'expressive' style of interaction than for instance people from Southern Europe (Pennebaker et al. 1996).

Secondly, task-oriented leadership is much less strongly related to communication styles than charismatic leadership and human-oriented leadership. Task-oriented leaders are characterized by assuredness and, more than charismatic and human-oriented leadership, by preciseness. However, 
in contrast with human-oriented and charismatic leadership, task-oriented leadership is also characterized by the presence of (some) verbal aggressiveness. An explanation of this finding may be that items pertaining to task-oriented leadership, more than items pertaining to human-oriented leadership and charismatic leadership, reflect content (e.g., rules, planning, and goal-setting) instead of style (e.g., friendliness, trust, and inspiration).

Thirdly, both the communication styles and leadership styles explain an almost comparable-the leadership styles slightly more-amount of variance in the outcome variables used in this study. The mediational analyses suggest that the relations of the communication styles with the leadership outcomes are statistically mediated by the leadership styles. One notable exception is leader's preciseness, which was found to have significant positive relations with perceived leader performance and satisfaction with the leader even when controlling for charismatic and human-oriented leadership. Additionally, leader's preciseness was, together with leader's supportiveness, the most important predictor of subordinate's knowledge collecting from a leader. Consequently, leader's preciseness seems to be an important construct, which is surprisingly absent in theories on leadership. Precise, or structured, communication is regarded as an important communication skill in for instance the medical sciences (Yedidia et al. 2003), but may be just as important in the supervision process. However, in contrast to doctors, there are no 'fixed' protocols for leaders which help them handle specific situations in a precise way. Instead, leaders may have to rely on more general 'conversation models' (Van der Molen and Gramsbergen-Hoogland 2005) to deal with different situations. Future studies might like to investigate the effects of training in communication skills - which are designed to help organizational leaders to practice and generalize different organizational 'conversation models' - on the preciseness with which leaders communicate (Baldwin 1992; Frese et al. 2003; Hunt and Baruch 2003; Towler 2003; Van der Molen and Gramsbergen-Hoogland 2005).

Leader's supportiveness seems to be the most important communication style variable, having positive relations with all of the leadership styles and outcomes, even after controlling for the other communication style variables. Supportive communication of a leader enhances knowledge donating behaviors to the leader and knowledge collecting behaviors from the leader. In the regression analyses, leader's assuredness was related to perceived leader performance, satisfaction with the leader, and subordinate's team commitment, but not to knowledge donating and collecting behaviors. Having a leader who radiates certainty may help to give a team direction and purpose, but may also cancel some of the positive effects in knowledge sharing situations by instilling uncertainty in employees who are willing to share or ask for information. In contrast with leader's supportiveness, leader's preciseness, and leader's assuredness, leader's argumentativeness had the weakest relations with the leadership styles and outcome variables. However, leader's argumentativeness was significantly related to charismatic leadership in the regression equation, which is notable, given the relatively low reliability of leader's argumentativeness and the fact that we did not distinguish between the different components of transformational leadership in this study. However, some of the items of charismatic leadership refer to visionary and intellectually stimulating leadership, which may involve an argumentative communication style.

Although there are several noteworthy findings in this study, it also has some limitations. Most importantly, it was impossible in this organization to obtain data from different sources or to use different methods to measure the predictor and criteria variables. Consequently, the outcomes may suffer from common method biases (Podsakoff et al. 2003). ${ }^{7}$ Note, however, that this is the first study of its kind to use a communication style framework based on the lexical paradigm in a study of leadership. Further research needs to be conducted to substantiate these findings using different methods and samples. A suggestion for future research is to construct an observational based measure of the six communication styles employed in this study and to use observers to rate the extent to which leaders employ these communication styles. In line with a recent study by Naidoo and Lord (2008), another suggestion is to use an experimental setting in which one or more of the communication styles are manipulated and the effects on perceived leadership and actual criteria are observed.

Although common method bias is a potential liability of this study, the results do show that in the assessment of charismatic and human-oriented leadership styles by subordinates, the leader's communication style seems to play a crucial role. Although the results do point out that, when explaining outcomes, measures of leadership styles are more parsimonious than measures of communication styles, a practical limitation of the use of leadership styles, such as charismatic leadership, instead of communication style measures, is that the leadership styles do not offer conceptual insights into the underlying (communicative) behavioral acts that take place in the interaction between the leader and the led (Yukl 1999). Furthermore, for training

\footnotetext{
$\overline{7}$ We did extract an acquiescence scale, which is a person's mean on all the (non-recoded) items in the questionnaire. Although this scale was not strongly related to the communication styles scales (which contain both positively and negatively worded items), it was strongly related to the traditional leadership scales (especially charismatic leadership and human-oriented leadership, which are unipolar), making the acquiescence scale confounded with systematic variance and unsuitable for further analyses.
} 
purposes, research into the communication styles of leaders is more likely to offer trainers and trainees clear guidelines to understand the behaviors that are likely to lead to positive results. By showing that charismatic and human-oriented leadership are to a considerable extent communicativeand task-oriented leadership is less communicative — and by showing the differential prediction of the communication styles, we believe this research offers an important foundation for the study and training of leadership.

Open Access This article is distributed under the terms of the Creative Commons Attribution Noncommercial License which permits any noncommercial use, distribution, and reproduction in any medium, provided the original author(s) and source are credited.

\section{References}

Allen, N. J., \& Meyer, J. P. (1990). The measurement and antecedents of affective, continuance and normative commitment to the organization. Journal of Occupational Psychology, 63, 1-18.

Ambady, N., LaPlante, D., Nguyen, T., Rosenthan, R., Chaumeton, N., \& Levinson, W. (2002). Surgeons' tone of voice: A clue to malpractice history. Surgery, 132, 5-9.

Awamleh, R., \& Gardner, W. L. (1999). Perceptions of leader charisma and effectiveness: The effects of vision content, delivery, and organizational performance. The Leadership Quarterly, 10(3), 345-373.

Baldwin, T. T. (1992). Effects of alternative modeling strategies on outcomes of interpersonal-skills training. Journal of Applied Psychology, 77(2), 147-154.

Baron, R. M., \& Kenny, D. A. (1986). The moderator-mediator variable distinction in social psychological research: Conceptual, strategic and statistical considerations. Journal of Personality and Social Psychology, 51, 1173-1182.

Bass, B. M. (1985). Leadership and performance beyond expectations. New York: Free Press.

Bienvenu, M. J. (1970). Measurement of marital communication. Family Coordinator, 19(1), 26-31.

Booth Butterfield, M., \& Booth Butterfield, S. (1990). Conceptualizing affect as information in communication production. Human Communication Research, 16(4), 451-476.

Bugental, D. B., Lyon, J. E., Lin, E. K., McGrath, E. P., \& Bimbela, A. (1999). Children "tune out" in response to the ambiguous communication style of powerless adults. Child Development, 70(1), 214-230.

Buller, M. K., \& Buller, D. B. (1987). Physicians' communication style and patient satisfaction. Journal of Health and Social Behavior, 28(4), 375-388.

Bultman, D. C., \& Svarstad, B. L. (2000). Effects of physician communication style on client medication beliefs and adherence with antidepressant treatment. Patient Education and Counseling, 40(2), 173-185.

Burgoon, J. K., Pfau, M., Parrott, R., Birk, T., Coker, R., \& Burgoon, M. (1987). Relational communication, satisfaction, compliancegaining strategies, and compliance in communication between physicians and patients. Communication Monographs, 54(3), 307-324.

Christensen, A. (1988). Dysfunctional interaction patterns in couples. In P. Noller \& M. A. Fitzpatrick (Eds.), Perspectives on marital interaction. Philadelphia, PA: Multilingual Matters.
Conger, J. A., \& Kanungo, R. N. (1988). Charismatic leadership: The elusive factor in organizational effectiveness. San Francisco, CA: Jossey-Bass.

Costa, P. T., \& McCrae, R. R. (1992). NEO Personality InventoryRevised (NEO-PI-R) and NEO Five-Factor Inventory (NEOFFI) professional manual. Odessa, FL: Psychological Assessment Resources.

Daft, R. L. (2003). Management (6th ed.). Cincinnati, OH: SouthWestern.

De Gilder, D., Van den Heuvel, H., \& Ellemers, N. (1997). Het 3componenten model van commitment. /A three component model of organizational commitment. Gedrag \& Organisatie, $10,95-106$

De Hoogh, A. H. B., Den Hartog, D. N., \& Koopman, P. L. (2004). The development of the CLIO: A questionnaire for measuring charismatic leadership in organizations / de ontwikkeling van de CLIO: Een vragenlijst voor charismatisch leiderschap in organisaties. Gedrag en Organisatie, 17, 354-382.

De Hoogh, A. H. B., Den Hartog, D. N., \& Koopman, P. L. (2005). Linking the Big Five-factors of personality to charismatic and transactional leadership; perceived dynamic work environment as a moderator. Journal of Organizational Behavior, 26(7), 839-865.

De Vries, R. E., Bakker-Pieper, A., Alting Siberg, R., Van Gameren, K., \& Vlug, M. (2009). The content and dimensionality of communication styles. Communication Research, 36, 178-206.

De Vries, R. E., Roe, R. A., \& Taillieu, T. C. B. (2002). Need for leadership as a moderator of the relationships between leadership and individual outcomes. The Leadership Quarterly, 13(2), 121-137.

De Vries, R. E., Van den Hooff, B., \& De Ridder, J. A. (2006). Explaining knowledge sharing: The role of team communication styles, job satisfaction, and performance beliefs. Communication Research, 33(2), 115-135.

DeGroot, T., Kiker, D. S., \& Cross, T. C. (2000). A meta-analysis to review organizational outcomes related to charismatic leadership. Canadian Journal of Administrative Sciences, 17, 356-371.

Den Hartog, D. N., House, R. J., Hanges, P. J., Ruiz-Quintanilla, S. A., Dorfman, P. W., \& Globe-Associates. (1999). Culture specific and cross-culturally generalizable implicit leadership theories: Are attributes of charismatic/transformational leadership universally endorsed? The Leadership Quarterly, 10, 219256.

Den Hartog, D. N., Van Muijen, J. J., \& Koopman, P. L. (1997). Transactional versus transformational leadership: An analysis of the MLQ. Journal of Occupational and Organizational Psychology, 70(1), 19-34.

Den Hartog, D. N., \& Verburg, R. M. (1997). Charisma and rhetoric: Communicative techniques of international business leaders. The Leadership Quarterly, 8(4), 355-391.

Dillard, J. P., Solomon, D. H., \& Palmer, M. T. (1999). Structuring the concept of relational communication. Communication Monographs, 66(1), 49-65.

Eden, D., \& Leviatan, U. (1975). Implicit leadership theory as a determinant of the factor structure underlying supervisory behavior scales. Journal of Applied Psychology, 60, 736-741.

Fleishman, E. A. (1953). The description of supervisory behavior. Journal of Applied Psychology, 37, 1-6.

Frese, M., Beimel, S., \& Schoenborn, S. (2003). Action training for charismatic leadership: Two evaluations of studies of a commercial training module on inspirational communication of a vision. Personnel Psychology, 56(3), 671-697.

Fuller, J. B., Patterson, C. E. P., Hester, K., \& Stringer, D. Y. (1996). A quantitative review of research on charismatic leadership. Psychological Reports, 78(1), 271-287. 
Galton, F. (1884). Measurement of character. Fortnightly Review, 36, $179-185$.

Goldberg, L. R. (1990). An alternative "description of personality": The Big-Five factor structure. Journal of Personality and Social Psychology, 59(6), 1216-1229.

Gudykunst, W. B., Matsumoto, Y., Ting Toomey, S., Nishida, T., Kim, K., \& Heyman, S. (1996). The influence of cultural individualism-collectivism, self construals, and individual values on communication styles across cultures. Human Communication Research, 22(4), 510-543.

Gudykunst, W. B., \& Ting Toomey, S. (1988). Culture and affective communication. American Behavioral Scientist, 31(3), 384-400.

Hailey, B. J., Willoughby, S. G., Butler, M. N., \& Miller, L. (1998). Effects of communication style on women's satisfaction with physicians. Psychology, Health \& Medicine, 3(4), 435-438.

Hall, E. T. (1976). Beyond culture. New York: Doubleday.

Hansford, B. C., \& Hattie, J. A. (1987). Perceptions of communicator style and self-concept. Communication Research, 14(2), 189203

Hawes, D. J. (1996). Who knows who best: A program to stimulate parent-teen interaction. School Counselor, 44(2), 115-121.

Hunt, J. W., \& Baruch, Y. (2003). Developing top managers: The impact of interpersonal skills training. Journal of Management Development, 22(8), 729-752.

James, L. R. (2008). On the path to mediation. Organizational Research Methods, 11, 359-363.

Judge, T. A., \& Bono, J. E. (2000). Five-factor model of personality and transformational leadership. Journal of Applied Psychology, $85(5), 751-765$.

Judge, T. A., \& Piccolo, R. F. (2004). Transformational and transactional leadership: A meta-analytic test of their relative validity. Journal of Applied Psychology, 89(5), 755-768.

Judge, T. A., Piccolo, R. F., \& Ilies, R. (2004). The forgotten ones? The validity of consideration and initiating structure in leadership research. Journal of Applied Psychology, 89(1), 36-51.

Kenny, D. A. (2008). Reflections on mediation. Organizational Research Methods, 11, 353-358.

Kirkpatrick, S. A., \& Locke, E. A. (1996). Direct and indirect effects of three core charismatic leadership components on performance and attitudes. Journal of Applied Psychology, 81, 36-51.

Leary, T. (1957). Interpersonal diagnosis of personality; a functional theory and methodology for personality evaluation. Oxford: Ronald Press.

Levin, D. Z., \& Cross, R. (2004). The strength of weak ties you can trust: The mediating role of trust in effective knowledge transfer. Management Science, 50(11), 1477-1490.

Levinson, W., Roter, D. L., Mullooly, J. P., Dull, V. T., \& Frankel, R. M. (1997). Physician-patient communication: The relationship with malpractice claims among primary care physicians and surgeons. Journal of American Medical Association, 277, 553-559.

Lord, R. G., de Vader, C. L., \& Alliger, G. M. (1986). A metaanalysis of the relation between personality traits and leadership perceptions: An application of validity generalization procedures. Journal of Applied Psychology, 71, 402-410.

Lord, R. G., \& Maher, K. J. (1993). Leadership and information processing: Linking perceptions and performance. New York: Routledge.

Lowe, K. B., Kroeck, K. G., \& Sivasubramaniam, N. (1996). Effectiveness correlates of transformation and transactional leadership: A meta-analytic review of the MLQ literature. The Leadership Quarterly, 7, 385-425.

Mathieu, J. E., \& Taylor, S. R. (2006). Clarifying conditions and decision points for mediational type inferences in Organizational Behavior. Journal of Organizational Behavior, 27, 1031-1056.

McCartney, W. W., \& Campbell, C. R. (2006). Leadership, management, and derailment: A model of individual success and failure.
Leadership \& Organization Development Journal, 27(3), 190_ 202.

McCroskey, J. C., Daly, J. A., Martin, M. M., \& Beatty, M. J. (1998). Communication and personality: Trait perspectives. Cresskill, NJ: Hampton Press, Inc.

Naidoo, L. J., \& Lord, R. G. (2008). Speech imagery and perceptions of charisma: The mediating role of positive affect. The Leadership Quarterly, 19, 283-296.

Noels, K. A., Clement, R., \& Pelletier, L. G. (1999). Perceptions of teachers' communicative style and students' intrinsic and extrinsic motivation. Modern Language Journal, 83(1), 23-34.

Noller, P., \& White, A. (1990). The validity of the communication patterns questionnaire. Psychological Assessment, 2, 478-482.

Norton, R. W. (1978). Foundation of a communicator style construct. Human Communication Research, 4(2), 99-112.

Penley, L. E., \& Hawkins, B. (1985). Studying interpersonal communication in organizations: A leadership application. Academy of Management Journal, 28(2), 309-326.

Pennebaker, J. W., Rimé, B., \& Blankenship, V. E. (1996). Stereotypes of emotional expressiveness of northerners and southerners: A cross-cultural test of Montesquieu's hypotheses. Journal of Personality and Social Psychology, 70(2), 372-380.

Podsakoff, P. M., MacKenzie, S. B., Lee, J. Y., \& Podsakoff, N. P. (2003). Common method biases in behavioral research: A critical review of the literature and recommended remedies. Journal of Applied Psychology, 88, 879-903.

Prisbell, M. (1994). Students' perceptions of instructors' style of communication and satisfaction with communication in the classroom. Perceptual and Motor Skills, 79(3), 1398.

Rasku Puttonen, H. (1988). Communication between parents and children in experimental situations. Jyväskylä Studies in Education, Psychology \& Social Research, 65, 1-71.

Riggio, R. E., Riggio, H. R., Salinas, C., \& Cole, E. J. (2003). The role of social and emotional communication skills in leader emergence and effectiveness. Group Dynamics: Theory, Research, and Practice, 7, 83-103.

Ritchie, L. D., \& Fitzpatrick, M. A. (1990). Family communication patterns-measuring intrapersonal perceptions of interpersonal relationships. Communication Research, 17(4), 523-544.

Rush, M. C., Thomas, J. C., \& Lord, R. G. (1977). Implicit leadership theory: A potential threat to the internal validity of leader behavior questionnaires. Organizational Behavior and Human Performance, 20, 93-110.

Schmid Mast, M., Hall, J. A., \& Roter, D. L. (2007). Disentangling physician sex and physician communication style: Their effects on patient satisfaction in a virtual medical visit. Patient Education and Counselling, 68(1), 16-22.

Shamir, B., Arthur, M. B., \& House, R. J. (1994). The rhetoric of charismatic leadership: A theoretical extension, a case study, and implications for research. The Leadership Quarterly, 5, 25-42.

Singelis, T. M. (1994). The measurement of independent and interdependent self-construals. Personality and Social Psychology Bulletin, 20(5), 580-591.

Sobel, M. E. (1982). Asymptotic confidence intervals for indirect effects in structural equation models. In S. Leinhardt (Ed.), Sociological methodology (pp. 290-312). San Francisco: JosseyBass.

Sorenson, R. L., \& Savage, G. T. (1989). Signaling participation through relational communication: A test of the leader interpersonal influence model. Group and Organization Studies, 14(3), $325-354$.

Spangler, W. D., \& House, R. J. (1991). Presidential effectiveness and the leadership motive profile. Journal of Personality and Social Psychology, 60, 439-455.

Srivastava, A., Bartol, K. M., \& Locke, E. A. (2006). Empowering leadership in management teams: Effects on knowledge sharing, 
efficacy, and performance. Academy of Management Journal, 49(6), 1239-1251.

Stewart, G. L. (2006). A meta-analytic review of relationships between team design features and team performance. Journal of Management, 32, 29-55.

Stone Romero, E. F., \& Rosopa, P. J. (2008). The relative validity of inferences about mediation as a function of research design characteristics. Organizational Research Methods, 11, 326-352.

Street, R. L. (2002). Gender differences in health care providerpatient communication: Are they due to style, stereotypes, or accommodation? Patient Education and Counseling, 48(3), 201206.

Syroit, J. (1979). Mens- en taakgerichtheid: Constructie en validering van een verkorte leiderschapsschaal [Human- and task-orientation: Construction and validation of a short leadership scale]. Gedrag, Tijdschrift voor Psychologie, 3, 176-192.

Takai, J., \& Ota, H. (1994). Assessing Japanese interpersonal communication competence. Japanese Journal of Experimental Social Psychology, 33(3), 224-236.

Towler, A. J. (2003). Effects of charismatic influence training on attitudes, behavior, and performance. Personnel Psychology, 56(2), 363-381.

Van den Hooff, B., \& De Ridder, J. A. (2004). Knowledge sharing in context: The influence of organizational commitment, communication climate and CMC use on knowledge sharing. Journal of Knowledge Management, 8(6), 117-130.

Van den Hooff, B., \& Hendrix, L. (2004). Eagerness and willingness to hare: the relevance of different attitudes towards knowledge sharing. Paper presented at the Fifth European Conference on Organizational Knowledge, Learning and Capabilities: Innsbruck, Austria.

Van der Molen, H. T., \& Gramsbergen-Hoogland, Y. H. (2005). Communication in organizations: Basic skills and conversation models. Hove, East Sussex: Psychology Press.

Van Dulmen, A. M., \& Bensing, J. M. (2002). Health promoting effects of the physician-patient encounter. Psychology, Health \& Medicine, 7(3), 289-300

Wiemann, J., Chen, V., \& Giles, H. (1986). Beliefs about talk and silence in cultural context. Paper presented at the Speech Communication Association convention, Chicago.

Yedidia, M. J., Gillespie, C. C., Kachur, E., Schwartz, M. D., Ockene, J., Chepaitis, A. E., et al. (2003). Effect of communications training on medical student performance. JAMA: Journal of the American Medical Association, 290(9), 1157-1165.

Yukl, G. (1999). An evaluation of conceptual weaknesses in transformational and charismatic leadership theories. The Leadership Quarterly, 10(2), 285-305. 